\title{
DUZU-QUERENÇA, SALINDA E LUAMANDA: UMA REPRESENTAÇÃO DA VIOLÊNCIA CONTRA A MULHER EM OLHOS D'ÁGUA, DE CONCEIÇÃO EVARISTO
}

\author{
Luciane de Lima Paim ${ }^{1}$ \\ Rosani Ketzer Umbach ${ }^{2}$
}

\begin{abstract}
Resumo: Olhos D'água é um livro de contos, vencedor do prêmio Jabuti, nessa categoria, em 2015, escrito por Conceição Evaristo. Nessa obra, a autora sacramenta, com uma linguagem sutil e poética, a pluralidade da existência humana. Em Olhos D'água, Conceição Evaristo ajusta o foco de seu interesse na população afro-brasileira abordando, sem meias palavras, a pobreza e a violência urbana que a acometem. O objetivo principal desse trabalho é analisar a forma como a autora representa a violência contra a mulher e as diversas formas de violências que as personagens femininas sofrem ao longo das narrativas. Como a obra escolhida é composta por 15 contos, com um vasto elenco de personagens femininas, nesse estudo, nos detemos em analisar apenas as personagens de Duzu-Querença, Salinda e Luamanda. Metodologicamente, analisamos excertos da obra, nos quais é mencionado como essas mulheres são vítimas de alguma forma de violência.
\end{abstract}

Palavras-Chave: Mulher. Violência. Opressão. Machismo.

Abstract: Olhos D'água is a short stories' book, winner of Jabuti award, in this category, in 2015, written by Conceição Evaristo. In this work, the author sacraments, with a subtle and poetic language, the plurality of the human existence. E, Olhos D'água, Conceição Evaristo adjusts the focus of her interest in the Afro-Brazilian people approaching, with no half-words, the poverty and the urban violence that affect them. The main goal of this work is alalyze the way the author represents violence against women and the several forms of violence that the female characters suffer througouth narratives. As the chosen work is composed by 15 short stories, with a wide cast of female characters, in this study, we focus in analyse only the characters of Duzu-Querença, Salinda e Luamanda. Methodologically, we analyse excerpts of the work, in which it's mentioned how these women are victims of some form of violence.

Keywords: Chauvinism. Woman. Oppression. Violence.

\footnotetext{
${ }^{1}$ Autora; Mestranda em Estudos Literários pela Linha de Pesquisa Literatura, Comparatismo e Crítica Social, do Programa de Pós-Graduação em Letras da Universidade Federal de Santa Maria (UFSM). E-mail: lucianeletras15@gmail.com

${ }^{2}$ Orientadora; Professora Dra. do curso de Letras e do Programa de Pós-Graduação em Letras da UFSM. E-mail: rosani.umbach@gmail.com
} 


\section{Introdução}

Se formos nos basear nas últimas notícias que estão em todas as plataformas da mídia, chegaremos à conclusão de que, por mais que avanços tenham sido conquistados, infelizmente, a sociedade brasileira ainda vive uma proliferação de violência contra a mulher. Mesmo com a sanção da Lei Maria da Penha, em 2006, hoje, contabilizam-se 4,8 assassinatos a cada 100 mil mulheres, número que coloca o Brasil no 5이 lugar no ranking de países nesse tipo de violação. Ainda, segundo o Mapa da Violência 2015, dos 4.762 assassinatos de mulheres registrados em 2013 no Brasil, 50,3\% foram cometidos por familiares, sendo que em 33,2\% destes casos, o crime foi praticado pelo parceiro ou ex-parceiro. Essas quase 5 mil mortes representam 13 homicídios femininos diários, em 2013.

É válido ressaltar que, nesta pesquisa, também, discutiremos sobre a discriminação racial, o que torna importante ressaltar que o mapa citado acima mostra que a taxa de assassinatos de mulheres negras aumentou 54\% em dez anos, passando de 1.864, em 2003, para 2.875, em 2013. Chama a atenção o fato de que, no mesmo período, o número de homicídios de mulheres brancas tenha diminuído 9,8\%, caindo de 1.747, em 2003, para 1.576, em 2013.

Os dados apontados mostram o quanto o passado ainda está impregnado em nosso dia a dia, pois apesar de lermos em revistas e jornais atuais sobre a violência contra a mulher, sabemos que ela já existia em séculos passados. Contudo, e felizmente, a Literatura, desde os seus primórdios e a cada dia de forma mais inovadora, tem nos presenteado com obras que tratam desse tema, para que assim a literatura seja (re)pensada, analisada e discutida, com o propósito de fazer o leitor refletir sobre assuntos como esse.

Assim sendo, esta pesquisa tem como objetivo analisar a forma como a autora representa a violência contra a mulher e as diversas formas de violências que as personagens femininas sofrem ao longo das narrativas. A obra selecionada é formada por 15 contos, com um grande elenco de personagens femininas, nesse estudo, nos detemos em analisar apenas as personagens de Duzu-Querença, Salinda e Luamanda.

Ainda, é pertinente destacar que Evaristo acaba trazendo aos seus leitores fatos sobre a vida de personagens femininas que sofrem ou sofreram algum tipo de 
violência, aproximando, assim, os leitores de fatos tão recentes que marcam o quando a sociedade ainda é violenta e machista. Pretendemos com essa pesquisa mostrar as diversas formas como uma narrativa pode apresentar temas, como racismo, violência contra a mulher, preconceito de gênero e de condição social.

Como base teórica nos detemos em conceituarmos o que é violência, e para isso nos apoiamos em Michaud (1989), em sua obra $A$ Violência. Além disso, em seguida, procuramos entender um pouco mais sobre as leis que amparam as mulheres e porque a persistência em violentá-las. Para isso, usamos, também, como base teórica a Lei Maria da Penha (2006), A Dominação Masculina, de Bourdieu (2015) e textos como o de Carlos Magno, Marcas da violência contra a mulher na literatura, dentre outros.

Ademais, independente dos resultados que serão obtidos com essa pesquisa, a violência contra a mulher é crime, e deve ser discutida, questionada, estudada e analisada. Portanto, os contos de Evaristo trazem à tona assuntos do nosso cotidiano, sobre os quais é necessário tratar.

\section{A autora e a obra: aspectos iniciais}

Conceição Evaristo é uma das principais expoentes da literatura brasileira e afro-brasileira atualmente. É mestra em Literatura Brasileira pela PUC-Rio e Doutora em Literatura Comparada pela Universidade Federal Fluminense. Tornou-se também uma escritora negra de projeção internacional, com obras traduzidas em outros idiomas. Publicou seu primeiro poema em 1990, no décimo terceiro volume dos Cadernos Negros, editado pelo grupo Quilombhoje, de São Paulo. Desde então, publicou diversos poemas e contos nos Cadernos, além de uma coletânea de poemas e dois romances.

Evaristo apresenta-nos uma literatura vasta de profundas reflexões acerca das questões de raça e de gênero, com o objetivo claro de revelar a desigualdade em nossa sociedade, além de recuperar uma memória sofrida da população afrobrasileira em toda sua riqueza e potencialidade de ação. 
É Uma mulher que tem cuidado de abrir espaços para outras mulheres negras se apresentarem no mundo da literatura. Pois como ela mesma disse em uma entrevista:

\begin{abstract}
"O que eu tenho pontuado é isso: é o direito da escrita e da leitura que o povo pede, que o povo demanda. É um direito de qualquer um, escrevendo ou não segundo as normas cultas da língua. É um direito que as pessoas também querem exercer. Então Carolina Maria de Jesus não tinha nenhuma dificuldade de dizer, de se afirmar como escritora. (...) E quando mulheres do povo como Carolina, como minha mãe, como eu, nos dispomos a escrever, eu acho que a gente está rompendo com o lugar que normalmente nos é reservado, né? A mulher negra, ela pode cantar, ela pode dançar, ela pode cozinhar, ela pode se prostituir, mas escrever, não, escrever é uma coisa... é um exercício que a elite julga que só ela tem esse direito. (...) Então eu gosto de dizer isso: escrever, o exercício da escrita, é um direito que todo mundo tem. Como o exercício da leitura, como o exercício do prazer, como ter uma casa, como ter a comida (...). A literatura feita pelas pessoas do povo, ela rompe com o lugar pré-determinado." (Conceição Evaristo, em entrevista concedida ao blog, Blogueiras Feministas - De olho na Web e no mundo, em 30 de setembro de 2010).
\end{abstract}

Olhos D'água é um livro de contos, vencedor do prêmio Jabuti, na categoria contos, em 2015, escrito por Conceição Evaristo. Nessa obra, a autora sacramenta, com uma linguagem sutil e poética, a pluralidade da existência humana. Em Olhos D’água, Conceição Evaristo direciona-nos a uma leitura focada no interesse na população afro-brasileira abordando, de forma clara e direta, a pobreza e a violência urbana que a acometem. No prefácio da $1^{\underline{a}}$ edição da obra, Heloisa Toller Gomes apresenta as personagens:

Sem sentimentalismos facilitadores, mas sempre incorporando a tessitura poética à ficção, os contos de Conceição Evaristo apresentam uma significativa galeria de mulheres: Ana Davenga, a mendiga Duzu-Querença, Natalina, Luamanda, Cida, a menina Zaíta. Ou serão todas a mesma mulher, captada e recriada no caleidoscópio da literatura em variados instantâneos da vida? Diferem elas em idade e em conjunturas de experiências, mas compartilham da mesma vida de ferro, equilibrando-se na "frágil vara" que, lemos no conto "O Cooper de Cida", é a "corda bamba do tempo". Na verdade, essa mulher de muitas faces é emblemática de 
milhões de brasileiras na sociedade de exclusões que é a nossa. (GOMES, 2011, p. 9-10).

Evaristo traz à tona, na obra supracitada, o realismo do cotidiano, o que muitas mulheres enfrentam e suportam. As personagens da obra escolhida sofrem violências verbais e físicas. Por isso, como parte dessa fundamentação teórica optamos por concentrar o recorte teórico-crítico na forma como a autora representa a violência contra a mulher, e as variedades de violências que as personagens femininas sofrem ao longo da narrativa.

\section{Analisando a representação da violência contra a mulher}

\subsection{A escolha das personagens violentadas}

O corpus dessa pesquisa, Olhos D'água, não é apenas mais um livro de histórias que conta as dificuldades enfrentadas, pelas minorias, em uma sociedade patriarcal, opressora e discriminatória. Nesta obra, Evaristo nos mostra, com toda sua humanidade, o que muitas pessoas viveram e, provavelmente, ainda vivem. Como a obra tem um vasto elenco, pois cada conto tem pelo menos cinco personagens, e na maioria personagens femininas, aqui, nos detemos em analisar a representação da violência contra a mulher em apenas três personagens.

A escolha dessas personagens se deu pelas formas como elas foram violentadas, uma vez que, ano nosso ver, foram elas que sofreram as violências mais cruéis. As personagens escolhidas são Salinda, Luamanda e Duzu-Querença, e para entender o porquê da nossa escolha, é necessário conhecer um pouco sobre a vida de cada uma.

Salinda era uma dona de casa, mãe e esposa. Com o passar do tempo de casada, ela começou a perceber que não era livre, não podia realizar suas vontades. Sua função era cuidar da casa, dos filhos e do esposo. Ela não tinha voz, quem mandava na casa era o marido. Quando Salinda percebe que estava presa na gaiola do casamento opressor, ela concluiu que era hora de se libertar e a passar a ver o mundo com os olhos de uma mulher livre e forte. 
Luamanda era mãe de cinco filhos, solteira, abandonada por todos os parceiros e parceiras. Luamanda considerava-se uma mulher livre, pois ela teve vários amores; homens, mulheres, qualquer um que se dispusesse em lhe dar amor, por mais que isso durasse apenas uma noite. O único problema é que essa liberdade, esses inúmeros amores deixaram muitas cicatrizes em seu corpo e em sua alma.

Duzu-Querença teve sua infância interrompida; enquanto as meninas de sua idade ainda brincavam de bonecas, ela era violentada pelos clientes da pensão onde morava. Em um mundo de pedofilia, violência e prostituição, Duzu começou a aprender sobre a vida, sobre o mundo e sobre como se defender. Virou prostituta por não ter voz, não ser ouvida todas as vezes que disse que foi estuprada. Acabou seus dias como uma mendiga, afinal seu corpo estava marcado e cansado demais para continuar trabalhando. Duzu-Querença não teve escolhas na vida, foi silenciada, atacada, violentada e abandonada.

É por essa representação de realidade violenta que essas personagens fazem parte dessa pesquisa. Evaristo, na sua imensa sabedoria com as palavras, apresentou aos seus leitores histórias que tocam nossa alma. Ela busca, de uma forma avassaladora e marcante, fazer com que os leitores percebam que sim, a violência ainda faz parte do nosso dia-a-dia, que sim, as crianças, muitas vezes não têm escolha. E é com essa visão de humanidade que as análises sobre a representação da violência contra mulher foram se construindo e que agora serão apresentadas.

3.2 Uma análise teórica que demonstra como Salinda, Luamanda e DuzuQuerença foram violentadas

Em Olhos D’água, Conceição Evaristo tenta trazer a tona o realismo do cotidiano, o que muitas mulheres enfrentam e suportam. As personagens da obra escolhida sofrem violências verbais e físicas. Por isso, para podermos comprovar e analisar a representação da violência contra a mulher, antes de qualquer coisa, precisamos estabelecer um conceito de violência. Segundo Yves Michaud, em sua obra "A Violência": 
Há violência quando, numa situação de interação, um ou vários atores agem de maneira direita ou idireita, maciça ou esparsa, causando danos a uma ou várias pessoas em graus variáveis, seja em sua integridade física, seja em sua integridade moral, em suas posses, ou em participações simbólicas e culturais (Michaud, 1989, p. 10-11).

Contudo, além de termos estabelecido um conceito de violência, precisamos, também, saber o que pode ou não ser considerado como violência contra a mulher, o foco desta pesquisa. Assim sendo, mostra-se pertinente que nos baseemos na Lei Maria da Penha para conhecermos um pouco mais sobre as definições de violência contra a mulher. Segundo o Art. 7ํ da Lei nํ⒒340/06 - Lei Maria da Penha:

São formas de violência doméstica e familiar contra a mulher, entre outras:

I - a violência física, entendida como qualquer conduta que ofenda sua integridade ou saúde corporal; II - a violência psicológica, entendida como qualquer conduta que the cause dano emocional e diminuição da autoestima ou que lhe prejudique e perturbe o pleno desenvolvimento ou que vise degradar ou controlar suas ações, comportamentos, crenças e decisões, mediante ameaça, constrangimento, humilhação, manipulação, isolamento, vigilância constante, perseguição contumaz, insulto, chantagem, ridicularização, exploração e limitação do direito de ir e vir ou qualquer outro meio que lhe cause prejuízo à saúde psicológica e à autodeterminação; III - a violência sexual, entendida como qualquer conduta que a constranja a presenciar, a manter ou a participar de relação sexual não desejada, mediante intimidação, ameaça, coação ou uso da força; que a induza a comercializar ou a utilizar, de qualquer modo, a sua sexualidade, que a impeça de usar qualquer método contraceptivo ou que a force ao matrimônio, à gravidez, ao aborto ou à prostituição, mediante coação, chantagem, suborno ou manipulação; ou que limite ou anule o exercício de seus direitos sexuais e reprodutivos; IV - a violência patrimonial, entendida como qualquer conduta que configure retenção, subtração, destruição parcial ou total de seus objetos, instrumentos de trabalho, documentos pessoais, bens, valores e direitos ou recursos econômicos, incluindo os destinados a satisfazer suas necessidades; $\mathrm{V}$ - a violência moral, entendida como qualquer conduta que configure calúnia, difamação ou injúria. (Art. $7^{\circ}$ da Lei $n^{\circ}$ 11.340/06 Lei Maria da Penha, 2006, p. 02). 
Com base nas teorias citadas passemos para a fase em que identificamos se houve ou não violência contra as personagens escolhidas. Focando primeiro no que Michaud considera violência, "há violência quando esta causa danos a um ou mais indivíduos em graus variáveis". (1989, p. 10-11), podemos dizer que todas as personagens sofrem violência. Para confirmar isso, vejamos passagens de cada personagem que vão ao encontro do que nos fala Michaud. Primeiro Salinda, que é vigiada pelo marido constantemente:

Além da ida ao trabalho, Salinda não podia sair só. Os filhos sem saber, tinham sido transformados em vigias da mãe. A viagem de regresso, que ela fez sozinha, foi controlada desde o momento em que deixou a casa da tia. No princípio, logo que começou a ser vigiada, chegou a pensar que estivesse sofrendo de mania de perseguição. Confirmou, porém, que estava sendo seguida, quando, numa noite, o marido, julgando que ela estivesse dormindo, falava alto na sala ao lado e sem querer ela ouviu todo o teor da conversa. Ele pedia notícias de todos os passos dela (EVARISTO, 2014, p. 53).

E com o número de ameaças crescendo, Salinda acabou tornando-se prisioneira dentro da própria casa.

Das perguntas maldosas feitas de maneira agressiva surgiu uma vigilância severa e constante que se transformou em uma quase prisão domiciliar. Ela respondeu com um jogo aparentemente passivo. Fingiu ignorar. Era apenas uma estratégia de sobrevivência. Ensaiava maneiras de se defender aguardando as crianças crescerem um pouco mais. Quando foi iniciado o cárcere doméstico, a menina que ele havia assumido como filha desde os onze meses tinha treze anos (EVARISTO, 2014, p. 55).

Luamanda, apesar de ser tão livre e ter tantos amores também teve o corpo e a alma marcados por atitudes violentas. Aqui nos detemos em apresentar a cena mais chocante desse conto.

Se havia o amor na vida de Luamanda, também um grande fardo de dor compunha as lembranças de seu caminho. A vagina ensanguentada, perfurada, violada por um fino espeto, arma covarde de um desesperado homem, que não souber entender a solidão da hora da partida. E durante meses, o sangue menstrual de Luamanda, sangue de mulher que nasce naturalmente de seu útero-alma vinha misturar-se ao sangue e pus, dádivas dolorosas que ela ganhara de um estranho fim amoroso. E pior do que a dor foi a dormência de que 
foi atacada, em sua parte tão viva, durantes meses a fio (EVARISTO, 2014, p. 62).

Essa cena é a mais marcante nesse conto, pois é aqui, que nós mulheres vemos, com olhos femininos, uma irmã de alma e útero ser violentada, atacada e vista como um objeto, que tinha dono. No momento que ela tenta mostrar que não é um objeto, não tem dono, é impossibilitada de sentir o que todos sentem: prazer. Aqui o prazer é substituído pela dor, e não só a dor física, mas também a dor espiritual, de não sentir um órgão tão vivo e símbolo de vida.

Duzu-Querença foi a mulher que menos teve escolhas na vida, afinal foi introduzida à vida adulta sem ao menos saber que estava adentrando nesse mundo. Duzu, ainda menina, foi morar em um prostíbulo sem saber. Ela via as cenas de sexo entre homens e mulheres e não entendia porque aquilo estava acontecendo ali onde ela morava. Até o dia em que, pela primeira vez, ela foi vítima de um pedófilo, pois, "Teve um momento em que o homem chamou por ela. Vagarosamente ela foi se aproximando. Ele, em cima da mulher, com uma das mãos fazia carinho no rosto e nos seios da menina." (EVARISTO, 2014, p. 33)

Curiosa, como sempre, Duzu continuou entrando nos quartos para espiar o que os casais faziam. Foi em um desses quartos que, "Um dia o homem estava deitado nu e sozinho. Pegou a menina e jogou na cama. Duzu não sabia ainda o ritmo do corpo, mas, rápida e instintivamente, aprendeu a dançar". (EVARISTO, 2014, p. 33). Duzu foi estuprada e silenciada, pois a voz dela não foi ouvida. Quando a dona do prostíbulo descobriu que o homem havia abusado da menina, ela não deu voz à menina, muito menos viu que aquilo era um estupro. Ela considerou que Duzu gostava do que fazia, e a partir desse dia ou a menina trabalhava como prostituta para ter casa e comida ou ela seria expulsa dali. Sem ter para aonde ir, sem saber o paradeiro dos pais, Duzu só tinha uma escolha, e foi assim que suas brincadeiras de boneca foram substituídas por roupas provocantes, preservativos e homens nus violentando seu corpo.

Por fim, ainda cabe identificarmos, sobre Salinda, Luamanda e DuzuQuerença, o que pode se enquadrar no artigo $7^{\circ}$ da Lei Maria Penha. Fica claro, em passagens do conto, que Salinda sofre violência psicológica. Sabemos que a violência psicológica é entendida: 
[...] como qualquer conduta que the cause dano emocional $e$ diminuição da autoestima ou que the prejudique e perturbe o pleno desenvolvimento ou que vise degradar ou controlar suas ações, comportamentos, crenças e decisões, mediante ameaça, constrangimento, humilhação, manipulação, isolamento, vigilância constante, perseguição contumaz, insulto, chantagem, ridicularização, exploração e limitação do direito de ir e vir ou qualquer outro meio que lhe cause prejuízo à saúde psicológica e à autodeterminação (§2. Art. $7^{\circ}$ da Lei ํo 11.340/06 - Lei Maria da Penha, 2006, p. 02).

O marido de Salinda não chega a violentá-la fisicamente, mas a forma como ele a trata, como a ofende, deixa claro que ela sobre violência psicológica.

Aos poucos as ameaças feitas pelo marido, as mais diversificadas e cruéis, foram surgindo. Tomar as crianças, matá-la ou suicidar-se deixando uma carta culpando-a. Salinda, por isso, vinha há anos adiando um rompimento definitivo com ele. Tinha medo, sentia-se acuada, embora às vezes pensasse que ele nunca faria nada, caso ela o deixasse (EVARISTO, 2014, p. 53).

Já Luamanda, apesar toda a liberdade, ainda acaba sendo violentada. Ela, como já apresentado, é agredida por um parceiro que não aceita o rompimento. Logo, Luamanda, segundo a Lei Maria da Penha, sofre violência física. Que segundo o $\S 1$, do artigo $7^{\circ}$ da Lei, é "entendida como qualquer conduta que ofenda sua integridade ou saúde corporal". (\$1. Art. $7^{\circ}$ da Lei $n^{\circ} 11.340 / 06$ - Lei Maria da Penha, 2006, p. 02).

Analisar a representação da violência contra a mulher, no conto de DuzuQuerença, com base na Lei Maria da Penha, só demonstra que, das três personagens escolhidas, ela é a mais violentada, pois o que acontece com ela configura violência física, psicológica, patrimonial, sexual e moral. Como o artigo $7^{0}$ da Lei Maria da Penha já foi citado, só podemos mostrar, com passagens da obra também já citadas, como Duzu se encaixa em todos os tipos de violência. Contudo, há um parágrafo que resume como Duzu viveu e o que sofreu.

Duzu morou ali muitos anos e de lá partiu para outras zonas. Acostumou-se aos gritos das mulheres apanhando dos homens, ao sangue das mulheres assassinadas. Acostumou-se às pancadas dos 
cafetões, aos mandos e desmandos das cafetinas. Habituou-se à morte como uma forma de vida (EVARISTO, 2014, p. 34).

Ainda sobre Duzu é válido prestarmos atenção sobre o que nos fala Bourdie, em A Dominação Masculina (2015), acerca dessa dominação de origem patriarcal.

[...] sempre vi na dominação masculina e no modo como é imposta e vivenciada, o exemplo por excelência [...] (da) submissão paradoxal, resultante daquilo que eu chamo de violência simbólica, violência suave, insensível a suas próprias vítimas, que se exerce essencialmente pelas vias [...] simbólicas da comunicação e do conhecimento, ou, mais precisamente, do desconhecimento, do reconhecimento, ou, em última instância, do sentimento (BOURDIEU, 2015, p. 7).

No caso de Duzu, a dominação masculina impediu a infância de uma criança, e a violência acabou tornando-se diária na vida dela.

Infelizmente, esses tipos de agressões contra as mulheres são recorrentes ao longo dos tempos. Historicamente, o mundo é um lugar desigual e a mulher acabou tornando-se prisioneira do poder masculino. A violência atinge mulheres de todas as classes sociais e independe de diferenças geracionais e de raça/etnia, mas como mostra o Mapa da Violência 2015, a taxa de assassinatos de mulheres negras aumentou 54\% em dez anos, passando de 1.864, em 2003, para 2.875, em 2013. Isso gera muitas discussões, pois quais seriam os aspectos (sociais, econômicos, culturais e políticos) e quais as circunstâncias geram mais violência contra a mulher negra?

Uma boa resposta seria a explicação que Aristóteles nos dá, em Política, onde a sociedade era dividida por homens livres e escravos, e por não terem cidadania as mulheres se juntavam aos negros em questão de ausência de direitos.

O que se pode concluir nessa situação é que a mulher é sempre reduzida a nada, porque vejamos: a sociedade era dividida em homens livres e escravos, os sem cidadania eram os negros, as mulheres e as crianças. Contudo, os negros poderiam obter a alforria, logo seriam livres. As crianças se fossem homens, iam crescer e adquirir cidadania. Mas e as mulheres? Independentemente da situação as mulheres continuariam sem voz e sem direitos. E outra questão inquietante: Se a mulher branca já era silenciada por causa do gênero, o que restava para a mulher negra? Nada? Ela simplesmente não faria parte da sociedade, não existiria? 
Talvez seja essa uma das respostas de porque a mulher negra ser mais violentada pela branca. Porque ainda vivemos em uma sociedade calcada nas estruturas patriarcais dos séculos passados, onde mulher não tinha voz, e se fosse negra, simplesmente, não existiria.

\section{Fendas conclusivas}

É considerável retomarmos que, na introdução da obra Marcadas a ferro Violência contra a mulher uma visão multidisciplinar, as organizadoras Márcia Castillo-Martín e Suely de Oliveira afirmam que:

No Brasil, a questão da violência contra a mulher ainda é um desafio a ser vencido. Todas as pesquisas mostram a gravidade do problema, afetando mulheres de todas as classes sociais, de diferentes credos, negras, brancas e indígenas; mulheres dos grandes centros urbanos e do interior do país. O Brasil é signatário de vários acordos internacionais que remetem direta ou indiretamente à questão da violência de gênero. Para o governo brasileiro, o enfrentamento à violência contra a mulher tem sido uma de suas prioridades e um compromisso de todos os dias (CASTILLOMARTÍN E OLIVEIRA, 2005, p. 14).

Assim sendo, percebemos que há muito a ser feito ainda, há muito que aprender. A sociedade precisa começar a aceitar a igualdade de gêneros, a respeitar o outro, a permitir o direito de liberdade às mulheres. Consideravelmente, muito já foi feito, as mulheres já conquistaram muito, contudo, é necessário que esse desejo de respeito não parta somente do sexo feminino. Talvez seja para isso que essa Literatura Contemporânea apresente-se repleta de humanismo e realismo, para que ela seja lida com o intuito de ser realizada uma reflexão sobre a realidade das mulheres na sociedade brasileira.

Muito se tem discutido sobre a literatura, enquanto produto, traçar um percurso delimitado pelo mercado editorial, que utiliza a violência e o realismo do cotidiano como estratégia de venda. Contudo, sem adentrar nessa discussão, esta pesquisa pode refletir sobre a utilização do realismo do cotidiano na obra escolhida. 
Dessa forma, concluímos sobre a pertinência de trabalhos como esse, que procurem mostrar a forma como a autoria feminina representa o realismo do cotidiano, as violências sofridas ao longo da vida, a interrupção das etapas da vida, os preconceitos enfrentados, diariamente, por homens e mulheres, independentemente da etnia ou da condição social. É através de autoras como Conceição Evaristo que se podem tratar temas tão delicados, como a violência contra a mulher, através de algo que, ao mesmo tempo em que possibilita uma apreciação estética, proponha ao leitor uma reflexão acerca do assunto abordado, que é a Literatura.

\section{REFERÊNCIAS}

ALGUNS números sobre a violência contra a Mulher. In: Compromisso e atitude. São Paulo: Qualitá Comunicações, 2016. Disponível em: <http://www.compromissoeatitude.org.br/dados-nacionais-sobre-violencia-contra-amulher/ $\geq$. Acesso em: 25 set. 2016.

ARAÚJO, Bárbara. Conceição Evaristo: literatura e consciência negra. Entrevista concedida com Blog Blogueiras Feministas, em 30 de set. de 2010. Disponível em:

http://blogueirasfeministas.com/2011/11/conceicao-evaristo/. Acesso em 30 de mar. de 2017.

ARISTÓTELES. Política. Tradução do grego, introdução e notas do Prof. Mário da Gama Kury. 3 ed.. Brasília: UNB, 1997.

BRASIL. Presidência da República. Secretaria Especial de Políticas para as Mulheres. Marcadas a Ferro - Brasília: Secretaria Especial de Políticas para as Mulheres, 2005. 260p.

BOURDIEU, Pierre. A dominação masculina. 13. ed. Rio de Janeiro: Bertrand Brasil, 2015. 160p.

CARTILHA: Conhecendo A Lei №. 11.340/06 - Lei Maria Da Penha, 2008. Disponível em:

http://www.pc.ac.gov.br/wps/wcm/connect/28e0df004a9f19f98420959841167f48/con hecendo_+maria_penha.pdf?MOD=AJPEREShttp://www.pc.ac.gov.br/wps/wcm/conn ect/28e00̄f004a9f19f98420959841167f48/conhecendo_+maria_penha.pdf?MOD=AJ PERES>. Acesso em: 26 maio. 2016.

EVARISTO, Conceição. Olhos D’água. Rio de Janeiro: Pallas: Fundação Biblioteca Nacional, 2014. 116p. 
GOMES, Carlos Magno. Marcas da violência contra a mulher na literatura. Revista Diadorim, UFRJ, Rio de Janeiro. Volume 13, Jul. 2013. Disponível em: <http://www.revistadiadorim.letras.ufrj.br/index.php/revistadiadorim/article/viewFile/29 0/252>. Acesso em: 30 set. 2016.

LEI MARIA DA PENHA. Presidência da República, 2006. Disponível em: < http://www.planalto.gov.br/ccivil_03/_ato2004-2006/2006/lei/l11340.htm>. Acesso em: 26 mai. 2016.

MICHAUD, Yves. A violência. São Paulo: Ática, 1989. 113p.

PERSONALIDADES Negras. Conceição Evaristo. Disponível em: http://www.palmares.gov.br/?page_id=27054. Acesso em: 30 mar. 2017

WAISELFISZ, Julio J. Mapa da Violência 2015: Homicídio de mulheres no Brasil. Brasília: FLACSO Brasil, 2015. Disponível em: <http://www.mapadaviolencia.org.br/pdf2015/MapaViolencia_2015_mulheres.pdf>. Acesso em: 24 set. 2016. 